\title{
Mães de Acari: o luto partido pela luta ou dos corpos negros e periféricos inelutáveis
}

\author{
Mães de Acari: grief broken by the struggle or the ineluctable \\ black and disenfranchised bodies \\ Malu Stanchi \\ malustanchi@gmail.com \\ Especializanda em Políticas Públicas e \\ Justiça de Gênero pelo Consejo \\ Latinoamericano de Ciencias Sociales \\ (CLACSO); Graduanda em Direito pela \\ PUC-Rio; Graduada em Artes Cênicas pela \\ UFRJ.
}

\section{Resumo}

A trajetória de luta das Mães de Acari reflete uma das possibilidades de resistência contra a estruturação do racismo institucional do Estado brasileiro. Executando ações programáticas de apagamento da população negra e periférica, as políticas estatais de (in)segurança produzem estigmas e ausências que a sociedade civil tenta superar e suprir para o resgate de ações de responsabilização, reparação e preservação da memória das vítimas da violência do Estado.

Palavras-chave: Política de segurança pública; racismo institucional; genocídio; população

\begin{abstract}
The struggle trajectory of the movement Mães de Acari reflects one of the possibilities of resistance against the structuring of the State's institutional racism. Carrying out programmatic actions to obliterate black and peripheral population, state (in)security policies produce stigmas and absences that civil society tries to overcome and supply to rescue the actions of accountability, reparation and preservation of the memory of victims of state violence.
\end{abstract}

Keywords: Public security policies; institutional racism; black genocide; human rights. 


\section{Introdução ou como começa a nossa caminhada}

Então, ser mãe é... eu acho que é construir assim, o mundo. ${ }^{1}$

Se nossos filhos fossem ricos e não negros, pobres e favelados, os culpados já teriam aparecido e nós teríamos sido tratadas de outra maneira. ${ }^{2}$

No escopo deste trabalho, optou-se por escolher o movimento de mulheres "Mães de Acari'" para abordar questões relativas às políticas de (in)segurança do Estado brasileiro. Partese da análise das dinâmicas da sociedade civil face às estruturais ações governamentais que engendram os jovens, negras e negros e periféricas/os como alvos diletos da violência histórica institucionalizada. Ao abordar a trajetória e estratégia de um dos movimentos de mães contra o genocídio da população negra, este ensaio reflete a tentativa de descolonizar epistemologicamente os debates sobre políticas de segurança pública e de espelhar uma das possibilidades de resistência às dinâmicas de execução e eliminação programática do Estado.

Sustentando a perpetuação do racismo silenciado e invisibilizado no cenário político nacional e internacional, as sistemáticas de violência estatal se reinventam através de novas ações, tecnologias e discursividades. Em oposição a este belicismo governamental racialmente endereçado, as organizações das mães de vítimas do Estado desempenham funções para suprir lacunas e ausências institucionais relacionadas ao cumprimento das devidas diligências investigatórias, ao indiciamento dos eventuais responsáveis e à construção de políticas de memória em prol das vítimas e seus familiares. Através da mobilização do Estado e do alerta à sociedade civil e às autoridades públicas sobre os abusos institucionais cometidos, as mães de vítimas trabalham cotidianamente pelo combate ao racismo institucional ${ }^{3}$ e às interfaces de seu necropoder ${ }^{4}$.

Um dos precursores das organizações de mães de vítimas do Estado, o grupo Mães de Acari deu ensejo às diversas configurações de movimentos marcados por estratégias de luta em

\footnotetext{
1 Depoimento sem identificação de Mãe de Acari (FREITAS, 2002, p.70).

2 Depoimento de Vera Lúcia Flores Leite, mãe de Cristiane Souza Leite, vítima da Chacina de Acari (BRAVO, 2019).

3 Jurema Werneck definiu o racismo institucional como "um modo de subordinar o direito e a democracia às necessidades do racismo, fazendo com que os primeiros inexistam ou existam de forma precária, diante de barreiras interpostas na vivência dos grupos e indivíduos aprisionados pelos esquemas de subordinação desse último" (2013, p.18).

${ }^{4} \mathrm{~A}$ atribuição de objetivos racionais ao ato de matar integra uma estruturada rede de políticas de dominação, que constituem características principais relacionadas ao necropoder. A necropolítica anuncia a exceção como facilitadora de estruturas da soberania, transgredindo e (des)orientando os limites elencados pelos próprios ordenamentos normativos dos Estados, que ratificam - para além das constituições e convenções publicizadas - o direito de matar, de deixar viver ou de expor à morte (MBEMBE, 2018).
} 
oposição à violência de Estado contra a população negra e periférica - como a Rede de Mães e Familiares da Baixada, o Movimento Moleque e a Rede de Comunidades e Movimentos contra a Violência - e deve ser referenciado como trajetória que transcreve muitos outros caminhos.

\section{Ressignificar trajetórias: o movimento}

Mas mesmo assim/ Ainda guarda o direito/ De algum
antepassado da cor/ Brigar sutilmente por respeito/
Brigar bravamente por respeito/ Brigar por justiça e por
respeito
Elza Soares, A carne

O movimento Mães de Acari surgiu na década de 1990, inserido no âmbito de muitas incidências de chacinas no Brasil. Formado por 11 mulheres negras - a maioria residente na Favela de Acari, no Rio de Janeiro - o Mães de Acari estruturou-se em virtude dos desaparecimentos forçados de Luiz Henrique Euzébio da Silva, 17 anos; Rosana Souza Santos, 18 anos; Edson de Souza, 17 anos; Hédio Oliveira do Nascimento, 30 anos; Cristiane Souza Leite, 16 anos; Wallace do Nascimento, 17 anos; Hudson de Oliveira Silva, 16 anos; Antônio Carlos da Silva, 17 anos; Viviane Rocha da Silva,13 anos; Moisés Santos Cruz, 26 anos; e Luiz Carlos Vasconcelos de Deus, 32 anos, sequestrados e mortos por um grupo de homens que se identificavam como policiais. As mães das vítimas da chacina de Acari são: Edimea da Silva Euzébio (mãe de Luiz Henrique Euzébio da Silva, 17 anos); Marilene Lima de Souza (mãe de Rosana Souza Santos); Vera Lúcia Flores Leite (mãe de Cristiane Souza Leite); Teresa de Souza Costa (mãe de Edson de Souza); Laudicena do Nascimento, a Dona Cena (mãe de Hédio Oliveira do Nascimento e avó de Wallace do Nascimento); Maria das Graças do Nascimento (mãe de Wallace do Nascimento); Euzilar Joana Silva Oliveira (mãe de Hudson de Oliveira Silva); Ana Maria da Silva (mãe de Antônio Carlos da Silva); Márcia da Silva (mãe de Viviane Rocha da Silva); Ednéia Santos Cruz (mãe de Moisés Santos Cruz); e Denise Vasconcelos (mãe de Luiz Carlos Vasconcelos de Deus). É preciso ressaltar que essas mães são referenciadas como "as precursoras na luta contra o extermínio de jovens negros e a violência policial. Fizeram sua voz e sua luta ser ouvida no Brasil e no mundo. Muitas delas faleceram sem ter tido justiça" (PLATAFORMA ALYNE, 2017).

A Chacina de Acari obteve repercussão notória entre os milhares de casos cotidianos de violência estatal contra a população negra e periférica (ANISTIA INTERNACIONAL, 2015). No episódio, 11 jovens foram retirados encapuzados de um sítio em Magé, na região 
fluminense, onde se encontravam para uma celebração. Entre as vítimas, 7 eram menores de idade. Os homens que invadiram a residência e realizaram o sequestro diziam ser policiais, quando, posteriormente, negociaram a libertação dos reféns com suas famílias.

À época, a mídia estigmatizou as vítimas, cunhando sobre elas paradigmas de criminalidade vinculados aos crimes contra o patrimônio e aos ilícitos de proibição de consumo e comercialização de entorpecentes. Uma das narrativas midiáticas atrelava a ocorrência do crime à tentativa dos sequestradores de extorquir dinheiro das vítimas e cobrar dívidas antigas relacionadas ao comércio de drogas. Uma das versões apresentava a seguinte abordagem:

Entre as muitas versões para o sequestro dos 11 rapazes e moças, as evidências parecem indicar que teria havido um banho, com o não pagamento a uma quadrilha de tóxicos, formada por policiais ou que teria cobertura da polícia. Uma das testemunhas afirmou em depoimento que no dia 14 de julho de 1990 policiais fardados do $9^{\circ} \mathrm{BPM}$ entraram na casa de Edméia da Silva Eusébio, mãe de um dos sequestrados, prenderam três adolescentes e exigiam $\mathrm{Cr} \$ 5$ milhões. Os policiais teriam dito então que se a quantia não fosse paga eles passariam o rodo (matariam todos). Mais tarde a extorsão foi reduzida para Cr\$ 2 milhões sendo que foram pagos Cr\$ 1 milhão e 800 mil por Luís Carlos (um dos desaparecidos). Na ocasião foram presos Moisés, Viviane e Edson, depois sequestrados em Magé. O restante do dinheiro ficou de ser pago dias depois, mas o grupo não completou o pagamento e fugiu para Magé. (...) Outra testemunha confirmou a invasão de policiais do $9^{\circ}$ Batalhão à casa de Edméia da Silva Eusébio, quando dois rapazes e uma menina (depois sequestrados) foram presos até o pagamento de Cr\$ 2 milhões - segundo a testemunha foram pagos 1 milhão 850 mil e os três liberados. Foram reconhecidos por fotos, como sendo autores da invasão e extorsão, os soldados Carlos Alberto de Souza Gomes, Eduardo José Rocha Creazola, Evaldo Barbosa do Nascimento, Paulo Roberto Borges da Silva e Wilton Elias da Cunha, todos do $9^{\circ}$ Batalhão, à época em que o Coronel Emir Larangeira era o comandante. (ARAÚJO, 2007, p.37-38)

Após as supostas negociações infrutíferas com o grupo de sequestradores, as vítimas foram alvo de desaparecimento forçado e o paradeiro dos seus corpos continua incerto. Apesar do tempo transcorrido desde o desaparecimento, o Estado permanece omisso quanto à emissão das certidões de óbito dos jovens, o que ofusca a possibilidade de uma versão oficial que admita a violência de Estado e racismo institucional contra as vítimas. Isso acaba por impedir a promoção de políticas de memória que orientem à não repetição dos fatos e impede o pleito das famílias por pensões e indenizações pecuniárias.

A ausência da devida diligência estatal também se refletiu nas escassas e infrutíferas investigações, e o inquérito sobre o desaparecimento das vítimas da Chacina de Acari foi encerrado em 2010, por falta de provas. Nenhum dos suspeitos do assassinato dos jovens foi 
indiciado (ANISTIA INTERNACIONAL, 2017, p.12). Contudo, os policiais que compunham o $9^{\circ}$ Batalhão de Rocha Miranda foram identificados como possíveis autores do crime, bem como integrantes de um grupo de extermínio denominado "Cavalos Corredores", conhecido pela entrada intempestiva nas favelas, invasão de domicílio e extorsão. Também foi apontado o envolvimento desse mesmo grupo de agentes públicos com a Chacina da Candelária e a Chacina de Vigário Geral, em 1993 (ANISTIA INTERNACIONAL, 2013).

Neste ínterim de violência estrutural e execuções extrajudiciais e sumárias contra jovens negros periféricos, e da consequente incapacidade do Estado brasileiro para a obtenção de justiça às vítimas de violência policial, as Mães de Acari construíram estratégias de luta, mobilização e busca pela verdade que inspiraram outros movimentos de mães de vítimas do Estado:

No repertório de ações desenvolvido pelas mães registra-se desde peregrinações por cemitérios clandestinos, penitenciárias, até escavações de sítios e supostas covas, passando por participações na novela Explode Coração a convite da autora e simpatizante da luta das mães Glória Perez, participação em um show de Roberto Carlos, até a gravação de clipes musicais como o de uma música de Marcelo Yuka (ex-integrante da banda carioca Rappa), e aparições no programa Linha Direta da Rede Globo, até viagens à Europa a convite das Mães da Praça de Maio e de Danielle Miterrand para participarem de um Encontro de Mães e fazerem um tour político. Entre a denúncia local e a denúncia internacional as "Mães de Acari" percorreram vários caminhos, mantiveram contatos com outras mães. Em 1994 as Mães da Praça de Maio juntamente com Danielle Miterrand organizaram o I Encontro de Mães de Desaparecidos, em Paris com lideranças políticas, artistas e construíram uma história de luta que mais tarde seria seguida por outras mães cujos filhos tiveram o mesmo triste fim. (ARAÚJO, 2007, p.56)

Desde atos públicos de repúdio à ineficácia da atuação das autoridades, rompimento com os estigmas de marginalidade cunhados pelo Estado e pela mídia contra as vítimas, luta pela preservação da memória dos seus filhos e investigações de próprio punho, iniciativa e recursos, as ações das Mães de Acari supriram lacunas consequentes do silenciamento do Estado e geraram a produção de novas provas sobre o caso e a notoriedade das denúncias. Contudo, mais uma vez, as mães foram vítimas da ação violenta do Estado, sofrendo retaliações irreversíveis:

Edméia, Marilene, Ana Maria, Vera Lucia, dentre outras mães, inconformadas com a impossibilidade de encontrar seus filhos e com a impunidade dos responsáveis, levantaram suas vozes a fim de dar visibilidade ao absurdo vivido por elas e à dor de não conseguir respostas sobre o paradeiro dos jovens. Assim surgiu o movimento "Mães de Acari". Na busca de seus filhos, elas percorreram cemitérios clandestinos, escritórios, instâncias burocráticas, 
Delegacias de Polícia, presídios; conversaram com juízes, delegados, secretários de segurança, autoridades policiais, ministros - sempre em busca de informações. Entretanto, até hoje sem sucesso. Em 2010, as investigações sobre o caso foram encerradas sem a denúncia dos responsáveis, devido à insuficiência de provas. Em janeiro de 1993, Edméia da Silva Euzébio, 47 anos, mãe de Luiz Henrique da Silva Euzébio e uma das mais empenhadas na luta por justiça, foi assassinada. (ANISTIA INTERNACIONAL, 2015, p.22)

Edméia da Silva Euzébio foi vítima de homicídio em uma emboscada no estacionamento do metrô da Praça Onze. Após transcorridos anos sem uma resposta conclusiva do Estado, a denúncia contra os supostos assassinos foi aceita pela justiça em 2011 (ANISTIA INTERNACIONAL, 2015, p.22). Atualmente, os sete acusados de matar Edméia da Silva Euzébio aguardam julgamento pelo Tribunal Popular ${ }^{5}$. O suposto mandante do homicídio é o coronel reformado da Polícia Militar e ex-deputado estadual, Emir Larangeira, chefe do grupo de extermínio indicado como provável responsável pela Chacina de Acari. Nos autos do processo, o Ministério Público expressa que:

Os crimes foram cometidos por motivo torpe, qual seja, vingança abjeta e demonstração de poder, pelo fato de a vítima exercer atividade de divulgação do crime da "Chacina de Acari", expondo as ações criminosas do grupo conhecido à época como Cavalos Corredores, do qual todos faziam parte. (TJRJ, Processo n. 0077862-16.1998.8.19.0001)

Até o momento, o caso não obteve esclarecimento dos fatos e identificação definitiva dos responsáveis pelo assassinato de Edméia, indicando a perpetuação das políticas de arbitrariedade estatal. Organizações da sociedade civil, contudo, continuam acompanhando os processos e pressionando as autoridades públicas para a devida busca pela verdade, pleiteando justiça, reparação e respeito à memória das vítimas da Chacina de Acari. Como aponta Jurema Werneck: "neste tempo (...) os possíveis responsáveis pela sua morte continuam andando livremente e progredindo em suas carreiras como policiais, alguns chegando a altos postos dentro da Polícia Militar" (ANISTIA INTERNACIONAL, 2018). Desse modo, parece haver a continuidade, oficial e oficiosa, da brutalidade estatal.

\footnotetext{
5 Ver Acórdão da Sexta Câmara Criminal do Tribunal de Justiça do Estado do Rio de Janeiro, acessando o Processo originário: 0077862-16.1998.8.19.0001(1998.001.078201-0). Disponível em: <http://www4.tjrj.jus.br/ConsultaUnificada/consulta.do\#tabs-numero-indice0>. Acesso em: 4 set 2019.
} 


\title{
Políticas de insegurança: as mães de vítimas da violência de Estado contra o genocídio da população negra
}

\begin{abstract}
A militarização da polícia e a banalização de direitos e garantias fundamentais em nome da segurança nacional fortaleceram a verve punitiva do Estado e, a despeito das narrativas hegemônicas, recaíram desproporcionalmente sobre corpos não brancos. (PIRES, 2018, p.1063)
\end{abstract}

\section{O Atlas da Violência de 2019 (FÓRUM BRASILEIRO DE SEGURANÇA PÚBLICA,} 2019, p.49) revelou que, em 2017, 75\% das vítimas de homicídio foram negras. Proporcionalmente, para cada indivíduo não negro que sofreu homicídio, 3 pessoas negras foram mortas, demonstrando o aumento significativo do índice de letalidade de pessoas negras no Brasil. Por meio de confrontos violentos e do uso da força bélica como léxico estatal, as políticas de segurança pública se reafirmam estruturando suas corporações a partir de um indicador central: a militarização da vida e a definição de alvos que têm cor e território identificados. O próprio Estado produz o medo que "justifica" institucionalmente as suas ações violentas, criando a base normativa do direito de matar através do apelo "à exceção, à emergência e a uma noção ficcional de inimigo" (MBEMBE, 2018, p.17).

As ações e intervenções estatais em favelas são justificadas institucionalmente através de discursividades que apregoam as atividades violentas desenvolvidas pelo Estado como única forma de proteção da "população de bem" e contra a "marginalidade". Engendrando a produção dos estigmas de periculosidade que embasam as intervenções em nome do resgate da lei e da ordem $^{6}$, as políticas de segurança pública estabelecem uma díade entre o cidadão e o inimigo, usurpando de humanidade todos os corpos cunhados como indesejáveis, perigosos, excedentes, inelutáveis:

Os estereótipos raciais e étnicos, mobilizados na prática da contenção criminal, desempenham papel incontornável na fundamentação das ações de violência policial. (...) No Brasil, devido à herança escravocrata e colonial, cujo corolário é o racismo institucional, praticado em todos os âmbitos da administração pública, a ameaça fantasmagórica encarnada no corpo negro tem como resposta um tipo violência profilática, física, psicológica e moral, desde o início desproporcional. (REIS, 2019, p.74)

\footnotetext{
${ }^{6}$ Para saber mais, ver, por exemplo, o pretenso plano estratégico da Intervenção Federal do Rio de Janeiro (BRASIL, 2018). Longe de uma atuação excepcional das Forças Armadas, a Intervenção foi instrumentalizada para acirrar o contexto de militarização e incursões violentas nos territórios periféricos, vivenciada diariamente pelos moradores desses locais. A Intervenção Federal do Rio de Janeiro constituiu-se sob um ato inconstitucional, que, sem a apresentação de um plano de ação e trabalho, vitimou de forma legítima e institucional milhares de pessoas nas regiões periféricas da cidade, principalmente jovens negros (OBSERVATÓRIO DA INTERVENÇÃO, 2019).
} 
Nessa perspectiva, a tentativa de apagar o passado, provocar a morte-em-vida, a morte física do presente e o extermínio do futuro se concretiza historicamente pela barbárie estatal contra corpos negros e periféricos, através da reinvenção de tecnologias segregacionistas que ultrapassam os status jurídicos e são naturalizadas nas relações sociais. Como apontou Abdias do Nascimento (1978), o racismo no Brasil é "eficazmente institucionalizado nos níveis oficiais de governo, assim como difuso no tecido social, psicológico, econômico, político e cultural da sociedade do país" (p.93). O genocídio da população negra em curso - "adequado aos propósitos da democracia racial dentro do sistema penal" (FLAUZINA, 2006, p.93) - é impulsionado pela construção da raça, herança colonial utilizada para legitimar a autorização da violência e a inferiorização da população negra a partir de padrões ficcionais de humanidade pautados no homem, branco, heterossexual e proprietário (PIRES, 2017).

A hierarquização de povos foi estabelecida pelo colonialismo, que desconsidera a humanidade da população negra, o que gera reflexos nos construtos relacionais incidentes nos processos cotidianos, como exemplificam as políticas de controle e segurança pública. Como evidencia Quijano (2014), a partir da sistemática do colonialismo foram produzidas dinâmicas que inauguram padrões de privilégio para os brancos, que se retroalimentam da subjugação, expropriação, apagamento e extermínio dos povos negros.

A década de 1990, período de grandes chacinas protagonizadas pela Polícia Militar, revelou uma dessas dinâmicas de subjugação racial e hierarquização de humanidades operada pela "branquitude", através do racismo institucionalizado. A atuação letal das forças policiais brasileiras, entretanto, não é nova. A novidade está na atualização das dinâmicas e sistemáticas do necropoder como prática e retórica da administração pública. Atualmente, evidencia-se o avanço, em proporções ainda maiores, de chacinas no Brasil, que, para serem noticiadas, precisam alcançar níveis exorbitantes de morte e violência - por vezes, celebradas como conquistas do governo para sua gestão e o combate à bandidagem ${ }^{7}$. Desse modo,

Atentando para as demais características do genocídio, podemos perceber como a população negra brasileira no Brasil está submetida a este tipo de procedimento. Dos homicídios irrefutáveis, passando pelas situações (...) que comprometem física e mentalmente os indivíduos e todas as debilidades forjadas para a sua fragilização e morte (...) a verdade é que essa é uma definição que se adequa perfeitamente à nossa realidade. No Brasil, o institucional tem sido mesmo um espaço privilegiado para a consecução de um projeto que se dá tanto por uma via ativa, em que todo o instrumental está

\footnotetext{
${ }^{7}$ Ver uma das declarações do atual governador do Rio de Janeiro, Wilson Witzel, sobre recentes ações policiais em Angra dos Reis em <https://www.bbc.com/portuguese/brasil-48190478>. Acesso em: 5 set 2019.
} 
voltado para a materialização do extermínio, quanto pelos sofisticados mecanismos de omissão, que deixam perecer aos montes os indivíduos a serem descartados. (FLAUZINA, 2006, p.119)

Enraizada nas políticas de segurança pública e nas reverberações sociais dos estigmas de criminalidade forjados sobre o corpo negro, a violência de Estado usurpa todos os aspectos da vida digna da população negra e periférica. Os movimentos de mães de vítimas do Estado se insurgem contra esta conjuntura de extermínio institucional, organizando-se em diversas redes e articulações. Como sinaliza Vilma Reis (2014), as mulheres negras "atuam para denunciar e remover as instituições do Estado Brasileiro de sua inércia, que mantém uma verdadeira máquina de morte, patrimonialista e guerreira, que tem como alvo preferencial jovens-homensnegros" (p.1). Pleiteando o esclarecimento dos casos de seus filhos assassinados pela mira da força policial, as Mães de Acari e tantos outros movimentos de mães demovem estruturas, denunciam o impronunciável e desvelam os reais atores e sistemáticas do genocídio dos jovens negros brasileiros.

\section{O luto partido pela luta}

Mas, sua dor não é reconhecida como dor válida. Como dor humana. Como dor política. (PIRES, 2018).

As Mães de Acari refletem e dão ensejo às muitas estratégias de resistência face ao extermínio estrutural da população negra e periférica. Fazendo frente às políticas de segurança pública, essas mulheres emergem contra esse modo de intervenção violenta do Estado, apresentando a maternidade como um signo em disputa. O luto, fruto da violência, não permite pausas. É vivenciado na luta por memória, justiça, verdade e reparação. Esse luto, substantivo e verbal, é inscrito pelas alianças mobilizadas com o intuito de cobrar do Estado brasileiro o reconhecimento pelas mortes de seus filhos, interrompido pela luta por esclarecimento dos fatos, pela busca de diligências investigatórias efetivas e pela tarefa imensurável de preservação das trajetórias e histórias das vítimas. Eis o luto das mães e familiares, que carrega os corpos negros imemoriais, não registrados por uma sociedade pautada pelos valores civilizatórios racistas. O luto que também pode ser considerado histórico. O luto político. 


\section{Referências bibliográficas}

ANISTIA INTERNACIONAL. 26 anos da Chacina de Acari. Rio de Janeiro: Anistia Internacional, 2016.

Muitas vozes lutando por direitos humanos. Brasil: Anistia Internacional. 2017. Disponível em: <https://anistia.org.br/wp-content/uploads/2017/07/almanaque_eej_edicaofinal.pdf> Acesso em: 30 ago 2019.

. Brasil: vinte e cinco anos de impunidade alimentam as mortes cometidas pela polícia do Rio de Janeiro. Brasil: Anistia Internacional, 2018. Disponível em: $<$ https://anistia.org.br/noticias/brasil-vinte-e-cinco-anos-de-impunidade-alimentam-mortescometidas-pela-policia-rio-de-janeiro/> Acesso em: 29 ago2019.

2013.

Chacina de Vigário Geral: vinte anos de impunidade. Brasil: Anistia Internacional,

Você matou meu filho: homicídios cometidos pela política militar na cidade do Rio de Janeiro. Rio de Janeiro: Anistia Internacional, 2015.

ARAÚJO, Fábio Alves. Do Luto à Luta: A experiência das mães de Acari. Dissertação dee Mestrado em Sociologia e Antropologia apresentada à Universidade Federal do Rio de Janeiro. Rio de Janeiro, 2007.

BRAVO, Cassiano Martines. 26 de julho lembra das Mães de Acari e seus filhos desaparecidos. Rio de Janeiro: Justificando, 2019. Disponível em: <http://www.justificando.com/2019/07/26/ 26-de-julho-lembra-das-maes-de-acari-e-seus-filhos-desaparecidos/> Acesso em: 29 ago 2019.

BRASIL. Plano Estratégico do Gabinete de Intervenção Federal. Brasília: Planalto, 2018. Disponível em: <http://www2.planalto.gov.br/mandatomicheltemer/acompanheplanalto/noticias/2018/06/plano-estrategicogif.pdf?TSPD_101_R0=7293cca259e81887ba31c5bf73c7ed16n180000000000000000896b11 c9ffff00000000000000000000000000005c8b70d00092749da108282a9212ab20002230665e9 863d145e388a9c2958dc7c8afe97083cd6793447dec467b7e30a03d0869cff3070a280086ce7c5 1ff436e6cadc97677d7ecce53bd22344ee64618f81ac0aa73f09d271c19abe68d37f1dd71> Acesso em: 12 set 2019.

CRUZ, Adriana. Sete acusados de matar líder das 'Mães de Acari' vão a júri popular. Rio de Janeiro: Justiça e Cidadania, 2019. Disponível em: $<$ https://justicaecidadania.odia.ig.com.br/colunas/justica-e-cidadania/2019/03/5629217-seteacusados-de-matar-lider-das--maes-de-acari--vao-a-juri-popular.html>. Acesso em: 4 nov 2019.

FLAUZINA, Ana Luiza Pinheiro. Corpo negro caído no chão: o sistema penal e o projeto genocida do Estado brasileiro. Dissertação de Mestrado em Direito apresentada à UNB. Brasília, 2006. 
FÓRUM BRASILEIRO DE SEGURANÇA PÚBLICA. Atlas da Violência 2019. Instituto de Pesquisa Econômica Aplicada; Fórum Brasileiro de Segurança Pública (Org.). Brasília: Rio de Janeiro; São Paulo: Instituto de Pesquisa Econômica Aplicada. Fórum Brasileiro de Segurança Pública, 2019.

FREITAS, Rita de Cássia Santos. Família e Violência: Reflexões sobre as mães de Acari. Revista Psicologia USP, v.13, n.2, p.69-103, 2002.

MBEMBE, Achille. Necropolítica: biopoder, soberania, estado de exceção, política da morte. Trad. Renata Santini. São Paulo: n-1 Edições, 2018.

NASCIMENTO, Abdias do. O genocídio do negro brasileiro: processo de um racismo mascarado. Rio de Janeiro: Paz e Terra, 1978.

OBSERVATÓRIO DA INTERVENÇÃO. Intervenção Federal: um modelo para não copiar. Rio de Janeiro: Centro de Estudos de Segurança e Cidadania da Universidade Cândido Mendes, 2019.

PIRES, Thula Rafaela de Oliveira. Direitos Humanos traduzidos em pretuguês. $13^{\circ}$ Mundo de Mulheres \& Fazendo Gênero 11. Florianópolis: UFSC, 2017. p.1-12.

Estruturas intocadas: racismo e ditadura no Rio de Janeiro. Revista Direito \& Práxis, v.9, n.2, p.1054-1079, 2018.

Não solte a minha mão, que eu não soltarei a de vocês. Empório do Direito, 2018. Disponível em: <http://emporiododireito.com.br/leitura/nao-solte-a-minha-mao-que-eu-naosoltarei-a-de-voces> Acesso em: 6 set 2018.

PLATAFORMA ALYNE. \#nuncamais. Rio de Janeiro: Alyne em defesa das mulheres negras, 2017.

QUIJANO, Aníbal. Colonialidad del poder, eurocentrismo y América Latina. In: PALERMO, Zulma; QUINTERO, Pablo (Orgs.). Aníbal Quijano: Textos de Fundación. Buenos Aires: Del Signo, 2014. p.109-158.

REIS, Diego dos Santos. O governo da emergência: Estado de Exceção, Guerra ao Terror e Colonialidade. Tese de Doutorado em Filosofia apresentada à UFRJ. Rio de Janeiro, 2019.

REIS, Vilma. Mulheres negras, criminalizadas pela mídia, violadas pelo Estado. São Paulo, 2014. Disponível em: <https://ponte.org/mulheres-negras-criminalizadas-pelas-midiasvioladas-pelo-estado/> Acesso em: 12 set 2019.

WERNECK, Jurema. Racismo Institucional: uma abordagem conceitual. São Paulo: Geledés Instituto da Mulher Negra, 2013. 